\title{
Influence of Factor Market Distortion on Carbon Emission Intensity: An Empirical Analysis
}

\author{
Ji Zhiying ${ }^{*}$, Nikita Shilov
}

SILC Business School, Shanghai University, Shanghai, China

DOI: $\underline{10.36348 / \text { sjef.2020.v04i09.007 }}$ | Received: 01.09.2020 | Accepted: 09.09.2020| Published: 19.09 .2020

*Corresponding author: Ji Zhiying

\section{Abstract}

There are both historical reasons for the distortion of factor market, and it is also resulted from inadequate marketoriented reform. Based on the static model and dynamic model, this paper studies the influence of factor market distortion on carbon emission intensity in China. The results show that the more serious the factor market distortion, the higher the carbon emission intensity. This result means that to improve environmental efficiency and reduce carbon emission intensity, we can start from correcting the distortion of factor market and deepening the reform of factor market. It is also found that the energy consumption structure is one of the significant factors affecting the intensity of carbon emissions. Reducing the proportion of coal consumption in the economy will help to improve China's energy efficiency. Based on the results of this study, relevant policy recommendations are put forward.

Keywords: Factor Market Distortion, Carbon Emission Intensity, Static panel data model, Dynamic panel data model.

Copyright @ 2020: This is an open-access article distributed under the terms of the Creative Commons Attribution license which permits unrestricted use, distribution, and reproduction in any medium for non-commercial use (NonCommercial, or CC-BY-NC) provided the original author and source are credited.

\section{INTRODUCTION}

The formation of factor market distortion is the product of China's economic and social development. China's economy has grown rapidly in the past 30 years, but this growth is based on the prerequisite of factor resources and the extensive growth achieved by capital accumulation. The growth model is supported by the distorted configuration of the factor market. Marketoriented elements of the market lagged behind the market, so that there is abnormal development trend in the price, this trend is not conducive to sustainable economic and social development. At the same time, environmental pollution has reached a point not to be underestimated, in which carbon emissions is an important issue plaguing sustainable development of China's economy, at present China is important at all levels of government and enterprises are faced with many ways to seek measures to reduce carbon intensity problem.

Currently, many literatures study the effects of factor market distortions on the economy in terms of inhibiting research and development, increased environmental pollution, suppression of industrial structure upgrading. In terms of the impact of factor market distortions on the environment, Kan University and Lu Lianju [1] found that factor market distortions and environmental pollution have spatial autocorrelation through the construction of a spatial dynamic panel model. Factor market distortions act on industrial structure, technological development, economic scale, corruption, and other ways to affect exports and foreign investment increased environmental pollution, improve the quality of the environment has a clear inhibitory effect; Zhang Yabin et al., [2] analyzed the spatial Durbin model and found that the factor market distortion behind economic growth will lead to aggravation of urban air pollution and have a negative spatial spillover effect on air quality. Various factors will flow in under the distorted price mechanism to areas with higher yields. Distortion of the factor market also inhibits the improvement of my country's energy efficiency, which causes the annual loss of energy to account for $24.9 \%-33.1 \%$ of the total energy loss. Also, factor market distortions caused by making the price undervalued backward production capacity has not been eliminated, the government allocated more inclined elements of affiliates and local enterprises, increasing the pressure on the environment, for our long-term development in negligible force [3]. Foreign scholars factor market distortions research focused on the problem of mismatch of resources, and factor market distortions due to the nature of the wrong distribution of resources, in particular capital factor and labor factor of distortion. Developing countries are more inclined to establish links with governments to obtain rent-seeking 
of the distribution rights of factor resources, thereby obtaining factor resources [4]. Chacholiades [5] showed that the inability of optimal allocation of factor resources caused by market imperfections is the main reason for the distortion of the factor market. This deviation in price from opportunity cost causes the long-term existence of distortions. Brandt et al., [6] believe that from the mid-1990s, China misallocation of resources presents a worsening phenomenon, and made clear that this trend is due to the labor market distortions caused, although later in the labor market's environment has gradually improved, but the magnitude of the improvement is still significantly lower than the degree of dispersion of total factor productivity between the various provinces.

\section{Measurement of factor market distortion and carbon emission intensity Measurement of Factor Market Distortion}

According to the existing literature, the measurement methods of factor market distortion include production function method, cutting-edge technology analysis method, shadow Price method, etc. This article needs to examine the impact of factor market distortions on carbon emission intensity. Therefore, it is necessary to measure the distortions in a real and effective manner, due to the lack of factor prices and inputs over the years. Existing literature refers more to the method of Zhang Jie et al., [7], that is, by using the indicators in the "Report on China's Marketization Progress Index-The Relative Progress of
Marketization in Various Regions 2011 Report" by Fan Gang et al., [8]: Overall Market Calculate the development degree of chemical index, product market and factor market. Indicators constructed as: FACTDIS1 = (degree of market development - the degree of development of factor markets) / market growth degree; FACTDIS2 $=$ (total market index - the factor market growth degree) / total market marketindex. This measurement method takes into account the fact that the development of the regional factor market lags behind the product market. However, through observation of the data of each region in each year, it is found that the development of the factor market is not completely independent, and it is not completely independent of the marketization index of the overall market. The development degree of the product market is highly correlated, and the correlation coefficients between the development degree index of the factor market and the marketization index of the overall market and the marketization index of the product market are 0.8993 and 0.6020 respectively [3]. Adopt the method Zhang Jie [3] proposed would make the relative degree of distortion between regions are smooth. Therefore, this draws Lin BoJiang and Duke Rui [3] of the measurement methods, i.e. the direct use of regional differences in the degree of development and market factors maximum degree of the sample obtained by subtracting factor market to market factors as the degree of distortion of the variables. The formula is expressed as:

$$
\text { FACTDIS }_{\text {it }}=\left[\max \left(\text { factor }_{\mathrm{it}}\right)-\text { factor }_{\mathrm{it}}\right] / \max \left(\text { factor }_{\mathrm{it}}\right) * 100
$$

Among them, factor ${ }_{i t}$ represents the factor market development degree of each region in each year, and $\max$ (factor ${ }_{\mathrm{it}}$ ) represents the maximum factor market development degree of the 30 provinces, autonomous regions and municipalities in the research sample from 2000 to 2009. The measurement of the degree of distortion in the factor market here is relative distortion, which can indicate the relative difference in the degree of distortion in the factor market between provinces and regions, and it also reflects its own changes with time.

\section{Carbon Emission Intensity Measurement}

Burning of fossil fuels is the primary source of carbon emissions, it is difficult to obtain due to the direct detection data of carbon dioxide, it is generally used in the study of the indirect route to obtain emissions data, including the carbon combustion chemical equation method or using the energy consumption to estimate carbon dioxide emission method etc. This article will draw on the method proposed by the United Nations Inter-Political Panel on Climate Change (IPCC) in 2006 to measure total carbon dioxide emissions by selecting the eight major fossil energy sources: raw coal, crude oil, natural gas, coke, gasoline, diesel, fuel oil and kerosene, and multiply the total consumption of each type of energy by their average low calorific value, the carbon content of energy unit calorific value, and the oxidation level of energy than carbon dioxide and molecular weight to calculate the carbon emissions, the specific formula is as follows:

$$
\mathrm{CO}_{2}=\sum_{i=1}^{n} E_{i} * N C V_{i} * C E F_{i} * C O F_{i} * \frac{44}{12}
$$

Among them, $i$ is the type of energy consumption (raw coal, crude oil, natural gas, coke, gasoline, diesel, fuel oil and kerosene); $N C V_{i}$ is the $i$ thenergy consumption; $N C V_{i}$ is the average low calorific value of the $i$-thenergy; $N C V_{i}$ is the The carbon content of the calorific value of the $i$ type of energy; $C O F_{i}$ is the oxidation level of the $i$ type of energy; 44 and 12 are the molecular weights of carbon dioxide and carbon, respectively.

The data on the consumption of various energy sources in various provinces comes from the "China Energy Statistical Yearbook"; the data on the average low calorific value of various energy sources comes 
from the national standard "General Principles for Calculation of Comprehensive Energy Consumption"; the carbon content and energy content oxidation level from the "2006 Guidelines for national greenhouse gas inventories."
The measurement of carbon emission intensity is based on the total carbon emission divided by the constant price GDP expressed by the price of 2000 . The specific formula is as follows:

\section{DATA, VARIABLES AND MODELS Data Description and Control Variable Selection}

The research samples, introduced in our paper, are 30 provinces, municipalities, and autonomous regions in China except Hong Kong, Macao, Taiwan and Tibet with the time period between 2000-2009, a total of 10 years. Considering that carbon emission intensity is affected by many other factors, when studying the impact of factor market distortions on carbon emission intensity, that's why five control variables that may have an impact on carbon emission intensity are selected.

Industrial structure (INDUSTRY): The proportion of the output value of the secondary industry in the regional GDP can reflect the economic development structure of the region. The secondary industry can be divided into manufacturing, mining, construction, electricity, gas, and water production and supply industries according to the "three-industry classification". According to the classification, the secondary industry, which is dominated by agriculture, has the characteristics of high energy consumption and high pollution compared with other types of industries. The proportion of the secondary industry has an inevitable relationship with the carbon emission intensity, where the main proportion states that the larger the proportion, the higher the corresponding carbon intensity. The data is selected from "China Statistical Yearbook", published annually.

Per capita GDP (PGDP): Per capita regional product is one of the important indicators to measure the regional economic development. It effectively measures the development process of the region. The per capita gross regional product is the ratio of the regional gross product during the accounting period (one year) of the country to the permanent population of the region. At the same time, for effective comparison, regional GDP adopts the GDP at constant prices in 2000. The higher the per capita GDP, the higher the overall importance of the region to the environment, and the lower the corresponding carbon emission intensity. On the other hand, in the Kaya carbon emission identity proposed by the United Nations InterPolitical Panel on Climate Change (IPCC) in 1989 by Japanese scholar Yoichi, the factors such as economy, population, and policies and carbon dioxide emissions are reflected by simple mathematical equations with strong interconnections between main variables described above. Therefore, this article takes GDP per capita as one of the control variables. The data comes from "China Statistical Yearbook", published annually.

Urbanization rate (URBEN): The proportion of urban population reflects by the total population of a region reflects the degree of urbanization in the region. Generally, the higher the degree of urbanization, the large-scale population agglomeration effect it brings, and this factor also will change the characteristics of energy consumption. The construction of public facilities such as transportation, housing, and medical equipment can better adapt to changes in urban population with the general mission to meet people's basic needs, a larger amount of energy has to be consumed, which leads to greater pollution. Simultaneously, urbanization can promote the improvement of energy efficiency and technological progress, alongside restrain the increase of carbon emission intensity. This article takes the proportion of urban population in the region as a proxy variable for the urbanization rate, referring to "China Statistical Yearbook", published annually.

Energy consumption structure (EC): The difference in the proportion of clean and highly polluting energy will inevitably have a big difference in the degree of environmental pollution. In our paper, the proportion of coal consumption in total energy consumption is used to measure regional energy consumption structure. The data comes from "China Energy Statistical Yearbook" with selected time series of 2000-2009.

The proportion of foreign direct investment (FDI): FDI flows to generate additional money outside of the FDI host's country, but also to strengthen cooperation and exchanges inside and outside, including high technology, advanced management concepts and so on. Advanced technological experience can promote the transformation of the domestic country's economic development model in a clean and intensive direction, thereby reducing the intensity of carbon emissions. However, taking into account another point of view, the direct investment of foreign funds is mainly concentrated in the relatively most polluting industries (mainly low-end manufacturing) in modern economy. As of 2000, China's foreign investment projects reach $72.99 \%$ and $60.87 \%$ of contractual investment between foreign and domestic investors are concentrated in industry. Developed countries continuously pay more attention to the environment in the development process, and transfer high-polluting 
and high-energy-consuming industries to developing countries, including Chinaby implementing foreign direct investment policy. There is no doubt that this will have a negative impact on the environment. From the above point of view, foreign direct investment has a dual effect on carbon emission intensity. The specific net effect is worthy of further analysis. Our paper uses the proportion of foreign direct investment in regional GDP as a proxy variable, and the proportion of FDI in this article is treated as a percentage $(\times 100 \%)$. The data is collected from "Statistical Yearbook" corresponding to each region with the time series of 2000-2009.

Table-1 below depicts the descriptive statistics of the factors such as the degree of distortion of the factor market, carbon emission intensity, industrial structure, GDP per capita, urbanization rate, energy consumption structure, and the proportion of foreign direct investment.

Table-1: Descriptive statistics results

\begin{tabular}{|l|l|l|l|l|l|}
\hline Variables & Observations & Mean & Std & Min & Max \\
\hline FACTDIS & 300 & 56.4075 & 20.0064 & 0.0000 & 94.8294 \\
\hline CARBON & 300 & 5.3832 & 3.8953 & 1.5614 & 21.5813 \\
\hline INDUSTRY & 300 & 46.6510 & 7.4242 & 19.8000 & 61.5000 \\
\hline PGDP & 300 & 1.3686 & 0.9548 & 0.2645 & 5.8407 \\
\hline URBAN & 300 & 44.4244 & 15.3395 & 23.2000 & 89.0900 \\
\hline EC & 300 & 69.1232 & 22.5341 & 26.0342 & 151.3896 \\
\hline FDI & 300 & 3.0174 & 2.6602 & 0.0847 & 15.3583 \\
\hline
\end{tabular}

\section{Measurement Model Setting}

In the construction of the econometric model, this article uses a combination of static panel models and dynamic panel models to more effectively study the impact of factor market distortions on carbon emission intensity, and chooses the random-effects GLS regression, Fixed-effects within regression, ArellanoBond dynamic panel-data estimation and system dynamic panel-data estimation, these four use more specific kinds of regression models to analyze the factors affecting the relationship between market distortions and carbon intensity.

\section{Static Panel Data Model}

In order to test the impact of factor market distortions on carbon emission intensity from an empirical point of view, we constructed the following static panel measurement model:

$$
\text { CARBON }_{\mathrm{it}}=\alpha_{0}+\alpha_{1} \text { FACTDIS }_{\mathrm{it}}+\beta_{1} \text { INDUSTRY }_{i t}+\beta_{2} \text { PGDP }_{i t}+\beta_{3} \text { URBAN }_{i t}+\beta_{4} E C_{i t}+\beta_{5} F D I_{i t}+\mu_{i}+\varepsilon_{\mathrm{it}}
$$

In the equation, $i$ and $t$ represent province and year respectively, the dependent variable CARBON $_{\text {it }}$ represents the carbon emission intensity of province $i$ in year $t$, and the core explanatory variable $F A C T D I S_{i t}$ represents the distortion degree of the factor market in province $i$ in year t, INDUSTRY $Y_{i t}$ represents the proportion of the secondary industry in province $i$ in year t, $P G D P_{i t}$ represents the per capita GDP of province $\mathrm{i}$ in year $\mathrm{t}$, and $U R B A N_{i t}$ represents the urbanization rate in province $\mathrm{i}$ in year $\mathrm{t}$, and $E C_{i t}$ represents the energy consumption structure of province $\mathrm{i}$ in year $\mathrm{t}, F D I_{i t}$ represents the proportion of foreign direct investment in province $\mathrm{i}$ in year $\mathrm{t}$, $\alpha_{0}$ represents the intercept term, and $\alpha_{1} 、 \beta_{1} 、 \beta_{2} 、 \beta_{3}$ 、 $\beta_{4} 、 \beta_{5}$ represent various variables The associated unknown parameter, $\varepsilon_{\mathrm{it}}$ represents the error interference term and includes the time effect $t$ and the individual effect i.

\section{Dynamic Panel Data Model}

Taking into account the relative stability of the economic development model, the inertial characteristics and path dependence of carbon emissions, the early carbon emissions will have an impact on the current carbon emissions, that is, the changes in carbon emissions are a slow, continuous and dynamic adjustment process. Therefore, the carbon emission intensity of this period will be affected by the carbon emission intensity of the previous period. In order to effectively characterize this persistent feature of carbon emission intensity and to test the robustness of the impact of factor market distortions on carbon emission intensity, in our paper, the first-order lag value of the dependent variable of emission intensity is used as an explanatory variable to construct the following dynamic panel model. An outstanding advantage of this model is that it can better overcome the problem of omitted variable and reverse causality by controlling the fixed effect, which is helpful to eliminate the endogenous bias and make the estimation result more reliable.

$$
\begin{aligned}
& \text { CARBON }_{\mathrm{it}}=\gamma \text { CARBON }_{\mathrm{it}-1}+\alpha_{1} \text { FACTDIS }_{\mathrm{it}}+\beta_{1} I N D U S T R Y_{i t}+\beta_{2} \text { PGDP }_{i t}+\beta_{3} \text { URBAN }_{i t}+\beta_{4} E C_{i t}+ \\
& \beta_{5} \text { FDI }_{i t}+\mu_{i}+\varepsilon_{\mathrm{it}} \ldots \ldots \ldots \ldots \ldots . .(5)
\end{aligned}
$$


Among them, CARBON $\mathrm{it}-1_{1}$ represents the onephase lagging term of the carbon emission intensity of the dependent variable, and $\gamma$ represents the coefficient corresponding to the lagging one-phase term of the carbon emission intensity of the dependent variable. The meanings of other variables and parameters in the model are different equations of the static panel model.

\section{ESTIMATION AND RESULT ANALYSIS Stationarity Test}

In order to avoid spurious regression and ensure the validity of the regression results, this article uses LLC-T test, Hadri test and HT test to test the stationarity of each variable. The LLC-T test refers to the deviation correction statistic proposed by Levin, Lin \& Chu, the Hadri test refers to the LM test statistic that extends the KPSS stationarity test to the panel data to be used for panel stationarity determination, and the HT test refers to Harris \& Tzavalis's test statistic based on fixed $T$ and $n \rightarrow \infty$. The unit root test results of each variable are shown in Table-2. It can be seen from Table-2 that, except for the PGDP variable which is not significant under the Harri test, all variables are significant at the level of $10 \%$, which shows that the variables studied in this paper do not have unit roots and are all stationary series.

Table-2: Variable stationarity test

\begin{tabular}{|l|l|l|l|l|}
\hline Variable name & LLC-T & Hadri LMstation & Harris-Tzavalis & Conclusion \\
\hline FACTDIS & $-5.6195 * * *$ & $4.8751 * * *$ & $0.2465 * *$ & Steady \\
\hline INDUSTRY & $-5.3103 * * *$ & $6.2798 * * *$ & $0.2716^{*}$ & Steady \\
\hline PGDP & $-3.8864 * * *$ & $13.0051 * * *$ & 1.0736 & Steady \\
\hline URBAN & $-5.2227 * * *$ & $3.5958 * * *$ & $0.2430 * *$ & Steady \\
\hline EC & $-6.2847 * * *$ & $2.3768 * * *$ & $-0.0198 * * *$ & Steady \\
\hline FDI & $-6.2189 * * *$ & $7.6867 * * *$ & $0.6058 * * *$ & Steady \\
\hline CARBON & $-5.2227 * * *$ & $7.7424 * * *$ & $0.2055^{* * *}$ & Steady \\
\hline
\end{tabular}

Note: $* * *, * *, *$ indicate significant at the level of $1 \%, 5 \%$ and $10 \%$ respectively.

\section{Estimation and Analysis}

This paper first uses the static panel model (4) to estimate the fixed effect parameters by gradually increasing the control variables. The results are shown in Table-3. Column (1) is the estimation result with only the control variable INDUSTRY added. The coefficient of FACTDIS is significantly positive at the $1 \%$ statistical level, indicating that the deepening of the factor market distortion will lead to the increase of carbon emission intensity. Column (2) adds the control variable PGDP, and the coefficient sign of the core explanatory variable remains unchanged and is valid at the $10 \%$ statistical level. The result (3) is the estimated result after adding the urbanization control variable, showing that the factor market distortion variable FACTDIS is significantly positive at the $10 \%$ statistical level. Column (4) is the regression result of adding all control variables. The coefficient of FACTDIS is significantly positive at the $1 \%$ statistical level. The above regressions all indicate that factor market distortions will promote the increase of carbon emission intensity. This result has not changed due to the difference in control variables, indicating that the results are robust and reliable. The estimated results of some control variables also have significant statistical significance. The impact of industrial structure INDUSTRY on carbon emission intensity is significantly positive at the $1 \%$ level, which shows that the greater the proportion of the secondary industry, the higher the carbon emission intensity. The impact of per capita GDP on carbon emission intensity shows that the increase in per capita GDP has a positive effect on improving carbon emission intensity. With the development of the economy and the increase of regional GDP per capita, people's requirements for environmental quality have further increased, and the concepts of environmental protection, energy saving and emission reduction have become more popular, which will promote the use of clean energy to reduce pollution. The energy consumption structure EC, that is, the proportion of coal consumption in total energy consumption has a significant positive impact on carbon emission intensity, and is significant at the $1 \%$ statistical level. 
Table-3: Panel data regression results of the impact of factor market distortions on carbon emission intensity

\begin{tabular}{|l|l|l|l|l|}
\hline & $(1)$ & $(2)$ & $(3)$ & $(4)$ \\
\hline FACTDIS & $0.0206^{* * *}$ & $0.00981^{*}$ & $0.0107^{* *}$ & $0.0191^{* * *}$ \\
\hline & $(0.00525)$ & $(0.00585)$ & $(0.00588)$ & $(0.00578)$ \\
\hline INDUSTRY & $0.0701^{* * *}$ & $0.0760^{* * *}$ & $0.0647^{* * *}$ & $0.0620^{* * *}$ \\
\hline & $(0.0170)$ & $(0.0167)$ & $(0.0187)$ & $(0.0172)$ \\
\hline PGDP & & $-0.438^{* * *}$ & $-0.567^{* * *}$ & $-0.304^{* *}$ \\
\hline URBAN & & $(0.115)$ & $(0.150)$ & $(0.151)$ \\
\hline & & & 0.0222 & 0.0192 \\
\hline EC & & & $(0.0168)$ & $(0.0154)$ \\
\hline & & & & $0.0540^{* * * *}$ \\
\hline FDI & & & & $(0.00723)$ \\
\hline & & & & 0.00845 \\
\hline Constant & 0.953 & $1.883^{* *}$ & 1.551 & $(0.0434)$ \\
\hline & $(0.969)$ & $(0.977)$ & $(1.007)$ & $(1.116)$ \\
\hline$N$ & 300 & 300 & 300 & 300 \\
\hline $\mathrm{R}^{2}$ & 0.0759 & 0.124 & 0.130 & 0.282 \\
\hline
\end{tabular}

Note: $* * *, * *, *$ indicate significant at the level of $1 \%, 5 \%$ and $10 \%$ respectively.

Table-4 is the estimation result for the dynamic panel model (5). In our paper, the characteristics of the data structure are that the time dimension is relatively short, and the lag term of the explained variable is introduced in the dynamic model, which leads to the correlation between the explanatory variable and the random disturbance item, and other explanatory variables may also have endogeneity problems. Therefore, both the random effect estimator and the fixed effect estimator are biased. In view of this method of estimating dynamic panel data model generally includes two categories: instrumental variables (IV), Anderson and Hsiao recommend using a first-order differential effect of eliminating the influence of the individual, then the dependent variable lagged two differential or entry lag two of the dependent variable as a dependent variable lagged instrumental variables to eliminate heterogeneity. Arellano believes that in the dynamic panel data model, if the difference variable is used as the instrumental variable, the parameter estimate with larger variance will be obtained, while the estimate obtained by using the horizontal instrumental variable (such as $y_{i, t-2}$ ) has a smaller variance; Another type of method is Generalized Moment Estimation (GMM). Arellano and Bover [9], Blundell and Bond [10] improved GMM and proposed a system generalized moment estimation (system GMM) method, which can be selected by the lag term of the first-order difference between the predetermined and endogenous variables is used as an instrumental variable to improve the Sargan test statistic for testing the rationality of instrumental variables. The important prerequisite for the consistency of the system GMM estimator is: the disturbance term after the first difference does not have the second order serial correlation, but the first order serial correlation is allowed. Therefore, we use the first-order and secondorder serial correlation tests AR (1) and AR (2) of the first-order difference conversion equation to judge whether the random disturbance term has serial correlation. In order to overcome the endogenous problem in the dynamic model, Arellano \& Bond [11] proposed a first-order difference GMM (differential generalized matrix method DIF-GMM) estimation method, that is, further difference processing of equation (5):

$$
\begin{aligned}
& \Delta \text { CARBON }_{i t}=\gamma \Delta \text { CARBON }_{\mathrm{it}-1}+\alpha_{1} \Delta F A C T \\
& \beta_{4} \Delta E C_{i t}+\beta_{5} \Delta F D I_{i t}+\Delta \varepsilon_{\mathrm{it}} \ldots \ldots \ldots \ldots \ldots \ldots
\end{aligned}
$$

This method can eliminate some variables that do not change with time after the difference is taken, and can prevent individual non-observation effects. At the same time, the inverse causal relationship between the independent variable and the dependent variable can be eliminated, effectively removing the endogenous problem. The result of model 5 is the result of regression of the model using DIF-GMM method. In our paper we firstly use STATA14 software to estimate the parameters of the system GMM for the measurement model (5). Columns (1) and (2) of Table 5 are based on the results of system GMM estimation.
Then the differential GMM estimation is performed based on the model (6), and the results are column (3) and column (4). The first condition for the estimation methods of differential GMM and system GMM is that the residual items must not have second-order serial correlation (first-order serial correlation is allowed), and pass the over-identification test. In Table 4, we can see that the Sargan test results show that the null hypothesis that "all instrumental variables are valid" cannot be rejected, which indicates that system GMM and differential GMM estimation can be performed. The test $\mathrm{P}$ value of $\mathrm{AR}(1)$ and $\mathrm{AR}(2)$ shows that the 
system GMM and differential GMM estimation cannot reject the null hypothesis that the model interference term has no second-order serial correlation, so the assumption that the disturbance term has no autocorrelation can be accepted, indicating that the system GMM and The estimation of the differential GMM is consistent.

In the regression results in Table-4, $\mathrm{L}$. CARBON represents the first-order lag term of carbon emission intensity. We can see that the first-order lag term of carbon emission intensity is significant at the statistical level of $1 \%$, which shows that carbon emission intensity is a slow, continuous and dynamic process. At the same time, it can be found from the results that under the dynamic model, the correlation coefficient value corresponding to the degree of factor market distortion is still positive, and it is significant at the statistical level of $1 \%$. This result shows that the factor market distortion promotes carbon emission intensity. Robust, the degree of distortion in the factor market has a clear positive impact on carbon emission intensity. The correlation coefficient of energy consumption structure (coal consumption proportion) is also positive and significant at the level of $1 \%$, which shows that the influence of energy consumption structure on carbon emission intensity is significant. The coefficients of the proportion of foreign direct investment in columns (2) and (3) are both positive and significant at the levels of $1 \%$ and $5 \%$, respectively. This shows that the increase in the proportion of foreign direct investment will lead to an increase in carbon emission intensity.

Table-4: GMM estimation results of the influence of factor market distortions on carbon emission intensity

\begin{tabular}{|l|l|l|l|l|}
\hline & $(1)$ & $(2)$ & $(3)$ & $(4)$ \\
\hline & SYS-GMM & SYS-GMM & DIF-GMM & DIF-GMM \\
\hline & $0.819^{* * * *}$ & $0.728^{* * * *}$ & $0.369^{* * * *}$ & $0.338^{* * *}$ \\
\hline FACTDIS & $(0.00293)$ & $(0.00427)$ & $(0.00424)$ & $(0.00497)$ \\
\hline & $0.0175^{* * *}$ & $0.0207^{* * * *}$ & $0.0179^{* * *}$ & $0.0211^{* * * *}$ \\
\hline INDUSTRY & $(0.000742)$ & $(0.00144)$ & $(0.000776)$ & $(0.00118)$ \\
\hline & -0.000405 & $-0.0307^{* * *}$ & $0.0223^{* * *}$ & $0.0302^{* * *}$ \\
\hline PGDP & $(0.00135)$ & $(0.00161)$ & $(0.00144)$ & $(0.00130)$ \\
\hline & $-0.103^{* * *}$ & $-0.111^{* * *}$ & $-0.346^{* * * *}$ & $0.154^{* * *}$ \\
\hline URBAN & $(0.0170)$ & $(0.0468)$ & $(0.0210)$ & $(0.0612)$ \\
\hline & & $0.0147^{* * *}$ & & $-0.0463^{* * *}$ \\
\hline EC & & $(0.00332)$ & & $(0.00442)$ \\
\hline & & $0.0356^{* * *}$ & & $0.0565^{* * * *}$ \\
\hline FDI & & $(0.000523)$ & & $(0.00137)$ \\
\hline & & $0.0241^{* * * *}$ & & $0.0176^{* * *}$ \\
\hline Sargantest_p value & 0.9583 & 0.9872 & 0.7910 & 0.8624 \\
\hline AR(1)_p value & 0.1466 & 0.1707 & 0.1619 & 0.2607 \\
\hline AR(2)_p value & 0.2817 & 0.3051 & 0.2765 & 0.3369 \\
\hline Constant & 0.115 & $-1.401^{* * * *}$ & $1.750^{* * *}$ & $-1.292^{* * *}$ \\
\hline & $(0.107)$ & $(0.160)$ & $(0.150)$ & $(0.258)$ \\
\hline$N$ & 270 & 270 & 240 & 240 \\
\hline
\end{tabular}

Note: Standard errors in parentheses; ${ }^{*} p<0.10,{ }^{* *} p<0.05,{ }^{* * *} p<0.01$

\section{SUMMARY AND POLICY RECOMMENDATIONS}

On the one hand, due to China's unique historical reasons and national conditions, the price of land, energy, labor, capital, etc. in the factor market is distorted. This distortion has led to a mismatch of resource elements, inhibiting technological and $R \& D$ progress, and industrial structure. Upgrades, energy efficiency improvements, etc., pose a threat to the environment that cannot be ignored; on the other hand, for the world, the negative impact of carbon emissions restricts social progress, and people's quality of life is also threatened. With the development of the economy, China's carbon emissions problem has become increasingly serious. Based on the above two facts, this paper selects the panel data of 30 provinces in my country except Hong Kong, Macao, Taiwan, and Tibet from 2000 to 2009 for empirical research. The factor market distortion measurement method draws on the measurement method proposed by Lin Boqiang and Du Kerui [3], and directly uses the measurement result of the relative difference between the development degree of the factor market in each region and the maximum value of the factor market development in the sample as the research in this paper as the main variables. Carbon emission intensity is calculated using the regional consumption of eight types of fossil energy, including raw coal, crude oil, natural gas, coke, gasoline, diesel, fuel oil, and kerosene. The consumption is multiplied by the average low calorific value of each energy; the carbon content and oxidation levels of the calorific value are used to calculate the total carbon emissions, 
and then the total carbon emissions are divided by the region's GDP at a constant price in 2000 to obtain the carbon emissions intensity. In the empirical analysis, this paper adds five control variables: industrial structure, per capita GDP, urbanization rate, energy consumption structure, and foreign direct investment proportion. The empirical results of static and dynamic panel data models respectively show that: factor market distortions will lead to increased carbon emissions intensity; energy structure, especially the proportion of coal consumption to enhance the inflow of foreign capital and will lead to increased carbon intensity.

Based on the research on the influence of factor market distortions on carbon emission intensity, this article has new inspiration for China's promotion of a low-carbon society. Since the "Eleventh Five-Year Plan" period, China has been mainly implementing "energy saving and emission reduction" administrative policies and measures to reduce carbon emissions, however, since the "Eleventh Five-Year Plan" period, various regional governments have adopted measures to "turn off electricity and limit electricity" in order to meet the hard requirements for energy conservation and emission reduction set by the state. This administrative measure of forcibly shutting down outdated production capacity can only reduce carbon emissions in short term, but it is not an effective measure in long run. Only by further improving the development of the factor market, accelerating the reform process of the factor market, and promoting the marketization of the allocation of factor resources can improve situation with carbon emissions more effectively. Our paper introduces the following strategies to reduce carbon emission intensity from the perspective of factor market reforms:

First, increase the reform mechanism of the factor market. The current marketization process of the factor market lags far behind the product market. To improve the carbon emission problem caused by the distortion of the factor market, the first task is to actively promote the reform of factor prices so that the factors The price in the market can be like the product market, according to the scarcity of factor resources and market demand, the market automatically adjusts the price, instead of the government controlling the price. In the allocation of resources, an open and transparent bidding method should be adopted, and the market should determine the price to reduce the possibility of rent-seeking. When a certain factor resource is scarce in the market, according to the market-oriented price determination method, companies can only survive in the market by accelerating $\mathrm{R} \& \mathrm{D}$ and technological progress and increasing resource utilization. This can promote the survival of the fittest, promote the upgrading of the overall industry, and the development of the enterprise's production development towards a clean and intensive development.
Second, the government reduces the administrative intervention of monopolization. For a long time, the almost monopolistic intervention of the Chinese government in factor resources has caused the factor market to show abnormal development. The monopoly effect of local governments and local stateowned enterprises on essential resources makes the allocation of resources impossible for the market. In order to have outstanding performance in the competition of political performance, local governments are more flexible to set up entry barriers between regions and support local enterprises as much as possible. On the one hand, it can achieve an increase in fiscal revenue such as taxation, and on the other hand, it can increase local GDP. These steps will crowd out foreign companies, which is not conducive to the development of marketization, and cannot achieve the optimal allocation of factor resources. Only by further standardizing government functions and reducing the control and intervention of factor resources can the factors circulate in the market more effectively. Enterprises have a fair opportunity to compete for element resources, which is conducive to promoting the enthusiasm of enterprises, and it is of great significance to structural upgrading and technological progress.

Third, establish an efficient and circulated labor market. As an important part of the factor market, labor force has long been distorted, and it is reflected in urban and rural distortions and industry distortions, mainly due to the inequality of labor income, welfare and rights. The distortion of labor factors restricts the flow of human resources in the market, which not only leads to the waste of production potential due to the inability of external excellent labor to enter monopoly industries, but also to the enthusiasm of laborers, and the capital investment for improving their own skills will be affected. Reduction is not conducive to the effective development of the entire society. Based on this, the construction of an efficient and circulated labor market can promote the effective allocation of factors and is an important direction for promoting social progress. On the one hand, People's Republic of China needs to vigorously improve the household registration system, accelerate the breaking of barriers between urban and rural areas, and reduce the occurrence of artificially lowering labor wages. To promote the marketization of labor factors, so that labor flows more freely between urban and rural areas, and in agricultural and non-agricultural industries. On the other hand, reducing labor trade distortions caused by administrative monopoly, reform deepening reform of state-owned monopoly enterprises, improve the enterprise's employment and remuneration system, prompting the labor factor can get a fair chance to compete. Labor factors circulate freely in the market, talents are widely used, and labor prices fluctuate with the market, which is conducive to the development of a sustainable society. 
Fourth, improve management of environment and natural resource elements. The production behavior of enterprises will bring about negative externalities of large pollution and energy consumption to the environment and natural resources. In order to develop the local economy, the government has been striving for more investment, at the expense of the local environment and natural resources, blindly lowering the local environmental protection standards, and penalizing enterprises that cause environmental pollution is not strong enough, making the environment polluted. And the cost of natural resources has been drastically reduced. In order to reduce environmental pollution and reduce carbon emission intensity, the government should set clear property rights for the environment and natural resources, and increase the prices of environmental and natural resource elements, so as to encourage companies that consume the environment and natural resources to accelerate their industry driven by profits, and force them to reduce pollution emissions.

Acknowledgments: The work is fully supported by the National Social Science Fund of China (No. 16BJY057).

\section{REFERENCE}

1. Da-xue, K. A. N., \& Lian-ju, L. (2016). The Study on the Home Market Effects of Sino-American Services Trade. International Business Research, (4), 10.

2. Ya-Bin, Z., Ying-Jie, L., Pei-Zhen, J. (2016). Spatial Effect of Factor Market Distortion on Chinese Urban Environmental Quality [J].
Collected Essays on Finance and Economics, (7): 3-10.

3. Lin, B., \& Du, K. (2013). The Energy Effect of Factor Market Distortion in China [J]. Economic Research Journal, 9:125-136.

4. Claessens, S., Feijen, E., \& Laeven, L. (2008). Political Connections and Preferential Access to Finance: The Role of Campaign Contributions [J]. Journal of Financial Economics, 88(3), 554-80.

5. Chacholiades, M. (1978). International Trade Theory and Policy [M]. New York: McGraw-Hill.

6. Brandt, L., Biesebroeck, J. V., \& Zhang, Y. (2009). Creative accounting or creative destruction? Firm-level productivity growth in Chinese manufacturing $[\mathrm{J}]$. Journal of Development Economics, 97(2): 339-351.

7. Zhang, J., Zhou, X., Li, Y. (2011). Does Factor Market Distortion Barrage Chinese Firms' R \&D? [J]. Economic research journal, 8:78-91

8. Fan, G., Wang, X., \& Zhu, H. (2011). China's marketization process by Region in 2011 [M]. Beijing: Economic Science Press, 265-285.

9. Arellano, M., \& Bover, O. (1995). Another look at the Instrumental Variable Estimation of Error Components Models [J]. Journal of Econometrics, 68(1):29-51.

10. Blundell, R., \& Bond, S. (1998). Initial Conditions and Moment Restrictions in Dynamic Panel Data Models [J]. Journal of Econometrics, 87(1):115143.

11. Arellano, M., \& Bond, S. (1991). Some tests of specification for panel data: Monte Carlo evidence and an application to employment equations. The review of economic studies, 58(2), 277-297. 